\title{
Localized Resectable Adult Liver Carcinoma
}

National Cancer Institute

\section{Source}

National Cancer Institute. Localized Resectable Adult Liver Carcinoma. NCI Thesaurus. Code C7877.

A localized hepatocellular carcinoma or intrahepatic cholang iocarcinoma that occurs during adulthood and it is amenable to surgical resection. 